\title{
Comparison of External and Internal Injury in Cases of Fatal Blunt Trauma Head Injury Autopsied at Tertiary Care Centre in Eastern Nepal
}

\author{
Bikash Sah, Bishwanath Yadav, Shivendra Jha \\ Department of Forensic Medicine and Toxicology, B. P. Koirala Institute of Health Sciences, Dharan, Nepal.
}

\author{
Correspondence \\ Dr. Bikash Sah \\ Assistant Professor, \\ Department of Forensic Medicine \\ and Toxicology, B. P. Koirala \\ Institute of Health Sciences, \\ Dharan, Nepal

\section{Email: \\ bikash.forensic@gmail.com}

\section{ORCID ID:}

http://orcid.org/0000-0002-6938-1425

DOI: http://dx.doi.org/10.3126/ jcmsn.v13i2.17697

Article received: $5^{\text {th }}$ Dec 2016 Article accepted: $8^{\text {th }}$ Apr 2017

\begin{abstract}
Background \& Objectives: Blunt trauma is more likely to be missed because clinical signs are less obvious in many regions of the body. This study was done with an objective to compare external and internal injuries of autopsy cases with fatal blunt trauma head injuries. Materials \& Methods: This was a hospital based, cross sectional and analytical study done on the autopsy cases at B. P. Koirala Institute of Health Sciences, Dharan, Nepal (tertiary hospital in eastern Nepal) from 13th April 2012 to 13th April 2013 with Head injuries by blunt trauma with or without concomitant non-head injuries. The decomposed bodies and the bodies where cause of trauma could not be differentiated were excluded. Postmortem examination was conducted on all the cases and the injuries present on all the body parts were noted. Abbreviated Injury Scale (AIS) score was given for each injury. Appropriate statistical tool was used to compare the AIS scores of external and internal injuries. The test of significance was fixed at $p<0.01$. Results:The correlation of scalp injuries with that of skull fracture, intracranial hemorrhage, cerebral injury and overall internal head injury were $0.591,0.772,0.439$ and 0.600 respectively and all these correlations were statistically significant whereas the correlation between concomitant external and internal nonhead injuries is -0.092 which is statistically not significant. Conclusion: This study has shown a statistically significant positive correlation between external and internal blunt trauma head injuries but there is no statistically significant correlation between concomitant external and internal non-head injuries .
\end{abstract}

Key words: Abbreviated Injury Scale (AIS); Comparison; Head Injuries

Citation: Sah B, Yadav BN, Jha S. Comparison of External and Internal Injury in Cases of Fatal Blunt Trauma Head Injury Autopsied at Tertiary Care Centre in Eastern Nepal. JCMS Nepal. 2017;13(2):246-50.

\section{INTRODUCTION}

Injury or trauma is divided into blunt and penetrating types. While penetrating trauma is usually diagnosed based on the clinical signs, blunt trauma is more likely to be missed because clinical signs are less obvious in many regions of the body. ${ }^{1}$ Head injuries occur in one-quarter to one-third of all accidental deaths, and in two-thirds of trauma death in hospitals. ${ }^{2}$ Head injury may result from motor vehicle accidents, falls from heights, assaults, pedestrians being struck by motor vehicles and so on. As a head injury occurs every 15 seconds and a patient dies due to head injury every 12 minutes, a day does not pass that an emergency doctor is not confronted with a head injured patient. ${ }^{3}$ It is difficult for both clinician and medicolegal experts to predict the extent and severity of internal injuries by just looking the external injuries. If internal injury severity can be predicted with the help of external finding, it will be much helpful for the clinician to choose an appropriate investigation, an effective treatment planning and to do a good prognosis. Similarly, it will be helpful for the medicolegal expert to make an appropriate medico-legal report like injury report. For this comparison, the severity of injuries are given Abbreviated Injury Scale (AIS) score and then AIS scores for external and internal injuries are compared. 
The AIS was first published in 1971. It was devised by a collaborative team comprising members from the American Association of Automotive Medicine, the Automotive Engineers Society, and the American Medical Association. The AIS is an anatomically based, consensus derived, global severity scoring system that categorises an individual injury by body region according to its relative severity on a six point scale that is AIS $1,2,3,4,5 \& 6$ as minor, moderate, serious, severe, critical and fatal injury respectively. ${ }^{4}$

If a relationship can be established between severity of external and internal injury with this study, then this relationship can be used as a guide as to widen the knowledge of the medical faculty in the field of early diagnosis, better management, good prognosis and for preparing a good medico-legal report. This study has been done to find out whether AIS score of internal injury produced by blunt trauma in the head region and concomitant non-head region can be significantly predicted by the AIS score of external head injury.

\section{MATERIALS AND METHODS}

This was a hospital based, cross-sectional and analytical study done on the autopsy cases. All the medico-legal cases presenting to the Department of Forensic Medicine and Toxicology at B. P. Koirala Institute of Health Sciences, Dharan, Nepal (tertiary hospital in eastern Nepal) from $13^{\text {th }}$ April 2012 to $13^{\text {th }}$ April 2013 with head injuries by blunt trauma with or without concomitant non-head injuries were included in the study. The decomposed bodies and the bodies where the cause of trauma could not be differentiated were excluded. The following data were collected; age, gender and cause of injury. Postmortem examination was conducted on all the cases and the injuries present on all the body parts were noted. Abbreviated Injury Scale (AIS) score was given for each injury as described in the Abbreviated Injury Scale 2005, Update 2008 scale book published by the Association for the Advancement of Automotive Medicine. ${ }^{5}$ Among internal head injuries that is skull fracture, intracranial hemorrhage and cerebral injury, the AIS score of one with the highest score was taken as AIS score for internal head injury. AIS scores for all injuries were tested for their normal distribution and then an appropriate test was used to compare external and internal injuries with a test of significance fixed at $p$-value $<0.01$. AIS score for scalp was compared with that of skull fracture, intracranial hemorrhage, cerebral injury and internal head injury. Similarly, AIS score for associated external and internal non-head injuries are also compared. Data Collection \& Statistical Method: Data were collected systematically in a detailed proforma developed for the postmortem evaluation of blunt trauma injuries. All collected data were compiled and entered into the Excel (Microsoft). Statistical Package for Social Sciences (SPSS) version 11.0 was used for analysis. Observations were recorded, analyzed and discussed. Ethical clearance was taken from the Ethical Committee of B. P. Koirala Institute of Health Sciences.

\section{RESULTS}

During the study period, 496 autopsies were done at the mortuary of B.P. Koirala Institute of Health Sciences. Seventy six (15\%) of them were the cases of fatal blunt trauma head injury. Road Traffic Accident (RTA) cases were $71 \%$ (54 out of 76), fall from height, $17.1 \%$ (13 out of 76), physical assault, $10.5 \%$ ( 8 out of 76 ) and roof collapse, $1.3 \%$ ( 1 out of 76). Among RTA victims, 53.7\% were pedestrians, $25.9 \%$ were on motorbikes, $11.1 \%$ were on four wheelers and $9.3 \%$ were on cycle. Male to female ratio was $3.7: 1$ and $69.8 \%$ of total blunt trauma head injury cases were within the age group of 11 to 50 years.

In order to apply appropriate statistical tool for comparing external injuries with the internal injuries, the normality test of AIS score for all injuries was done. A Shapiro-Wilk's test $(p<0.05)^{1,2}$ and a visual inspection of their histograms, normal Q-Q plots and box plots showed that AIS scores for scalp injury, skull fracture, intracranial hemorrhage, cerebral injury, internal head injury, associated external and internal non-head injuries with their respective skewness and Kurtosis ${ }^{3,4,5}$ as shown in Table 1 were not normally distributed. Spearman rho correlation was used to see the correlation between AIS score of external and internal head injury and associated non-head injury. It was found that there was a positive correlation with moderate strength between AIS score of scalp injury and of skull fracture, of intracranial hemorrhage and of internal head injury whereas with strong strength between AIS score of scalp injury and of cerebral injury (Table 2). These all correlation are statistically significant (Table 2). But there was a negative correlation between AIS score of associated external and internal non-head injury and this correlation is not statistically significant (Table 2) 


\section{DISCUSSION}

It is not a good way of practicing medicine in a defensive manner that is prescribing all wanted and unwanted investigations. It becomes even more important if it is the case of head injury. If computed tomography (CT) scan is being prescribed in every case of head injury produced by blunt trauma, then in one hand, patients who are not with any internal injuries are being unnecessarily exposed to the radiation then on another hand, they are forced to bear an undue economic burden. When medical paternalism was normal, the patients complied with clinicians' orders without raising any question. Today is the era of informed consent system where clinicians are required to show an indication for any procedure. This study, with an objective to establish a relationship between external and internal blunt trauma head injuries, may add a point in the existing indications for CT scan in blunt traumatic head injury cases. Our study has shown that the relationship between external injuries of the head are more predictive of internal injuries than external injuries elsewhere. This finding was supported by many other studies. ${ }^{11,14}$ In a study done by Yartsev and Langlois, ${ }^{11}$ the relationship between external and internal injuries was examined, with the aim of determining whether potentially fatal internal injuries could be inferred from external findings alone. From 291 postmortem cases, the external and internal injuries were coded according to region, type and severity. In this study, the overall correlation between external and internal injuries was poor. The best predictive external injuries were multiple lacerations, large abrasions with lacerations, and gross alterations. Predictably, the most severe external injuries were the most reliable predictors of lethal internal injuries. External injuries of the head were more predictive of internal injuries than external injuries in other parts of the body. Minor external injuries like small abrasions, bruises or small lacerations did not predict fatal internal injuries. In a study done in Japan, reported two cases where traffic accidents cause unexpectedly severe injuries of internal organs despite tiny injuries observed on the external body. One case had subcutaneous and intramuscular bleeding with decollement on the posterior aspect of her body, including upper cervical spine dislocation. Another case did not exhibit any obvious findings on postmortem examination that were indicative of a direct injury by a motor vehicle, but had severe internal organ injuries, including the transaction at ponto-medullary junction. ${ }^{12}$ Studies have shown that almost half of the autopsies performed on victims of traffic accidents, especially accidents involving pedestrians, reveal the presence of mild external injuries and severe internal injuries. ${ }^{13}$

This study has shown a positive correlation with moderate strength between AIS score of scalp injury with that of skull fracture, of intracranial hemorrhage and of internal head injury whereas there is a positive correlation with strong strength between AIS score of scalp injury and of cerebral injury (Table II) and all correlation done for head injuries are statistically significant. In this way, the severity of internal injury of head region can be predicted with the help of external injury and thus help both clinicians and medico-legal experts. At the same time, correlation between AIS score of associated external and internal non-head injury was negative. This shows that there may be a severe internal injury even for milder/no external injury or there may be no/milder internal injury even for severe external injuries but this correlation is statistically not significant. Similar finding was also

Table 1: Normality Test

\begin{tabular}{lll} 
AIS Score & Skewness (Standard Error) & Kurtosis (Standard Error) \\
Scalp injury & $0.626(0.276)$ & $-0.847(0.545)$ \\
Skull Fracture & $0.179(0.316)$ & $-1.859(0.623)$ \\
Intracranial Hemorrhage & $-0.824(0.285)$ & $0.015(0.563)$ \\
Cerebral Injury & $0.369(0.434)$ & $-2.007(0.845)$ \\
Internal Head Injury & $0.140(0.276)$ & $-0.385(0.545)$ \\
$\begin{array}{l}\text { Associated External Injury on other } \\
\text { part of body }\end{array}$ & $0.968(0.311)$ & $3.483(0.613)$ \\
$\begin{array}{l}\text { Associated Internal Injury on other } \\
\text { part of body }\end{array}$ & $0.064(0.314)$ & $-1.177(0.618)$ \\
\hline
\end{tabular}


Table 2: Comparison of External and Internal Injury

\begin{tabular}{|c|c|c|c|c|c|}
\hline AIS Score & $\begin{array}{l}\text { Maximum } \\
\text { AIS Score }\end{array}$ & $\begin{array}{l}\text { Minimum } \\
\text { AIS Score }\end{array}$ & $\begin{array}{l}\text { Median } \\
\text { (IQR) }\end{array}$ & $\begin{array}{l}\text { Correlation } \\
\text { Coefficient (r) }\end{array}$ & $\begin{array}{l}\text { P } \\
\text { value*** }\end{array}$ \\
\hline Scalp Injury & 3 & 0 & $1(0-2)$ & \multirow{2}{*}{0.591} & \multirow{2}{*}{0.001} \\
\hline Skull Fracture & 4 & 2 & $3(2-4)$ & & \\
\hline Scalp Injury & 3 & 0 & $1(0-2)$ & \multirow{2}{*}{0.439} & \multirow{2}{*}{0.001} \\
\hline Intracranial Hemorrhage & 5 & 2 & $4(4-4)$ & & \\
\hline Scalp Injury & 3 & 0 & $1(0-2)$ & \multirow{2}{*}{0.772} & \multirow{2}{*}{0.001} \\
\hline Cerebral Injury & 6 & 4 & $4(4-6)$ & & \\
\hline Scalp Injury & 3 & 0 & $1(0-2)$ & \multirow{2}{*}{0.600} & \multirow{2}{*}{0.001} \\
\hline Internal Head Injury & 6 & 2 & $4(4-6)$ & & \\
\hline Associated External Injury & 3 & 0 & $1(1-1)$ & \multirow{2}{*}{-0.092} & \multirow{2}{*}{0.494} \\
\hline Associated Internal injury & 6 & 0 & $2.5(1-5)$ & & \\
\hline
\end{tabular}

presented by de la Grandmaison GL et a ${ }^{14}$ where the cause of death based on external examination is mostly erroneous indicating that the determination of the basic and/or underlying cause of death is significantly more accurate when an autopsy is performed. The necessity of internal examination as a part of forensic examination was also shown in the study done by Subedi et al. ${ }^{15}$ Studies have shown that in order to discover the true extent of diseased person's injuries, one must explore the interior of their body. ${ }^{11,16}$

\section{CONCLUSION}

This study has shown a statistically significant positive correlation between external and internal blunt trauma head injuries but there is no statistically significant correlation between concomitant external and internal non-head injuries. Thus one can predict severity of internal head injuries with the help of external finding which is not possible for non-head injuries condition.

\section{ACKNOWLEDGEMENTS}

I would like to thank Dr. Nuwadatta Subedi, Dr. Sharmila Gurung, Dr. Sanjay Sah, Dr. Abdul Sami Khan, Dr. Prakash Chandra Panjiyar, Mr. Naveen Sah, Mr. Rampriti Sah, Mr. Ugranarayan Yadav, Mr. Jitendra Uraw, Mr. Jay Prakash Uraw and Mr. Ram Prasad Uraw for their help during my study. My heartfelt thank is for the deceaseds on whom this study is done and their relatives who gave me permission for this study.

\section{REFERENCES}

1. Jansen JO, Yule SR, Loudon MA. Clinical Review: Investigation of blunt abdominal trauma. BMJ. $2008 \mathrm{Apr}$ 26; 336(7650): 938-942. https://doi.org/10.1136/ bmj.39534.686192.80

2. Jennett B. Epidemiology of head injury. Archives of Disease in Childhood. BMJ. 1998 May 1;78(5):403-6. https://doi.org/10.1136/adc.78.5.403

3. Scwartz GR: Trauma to the Head. Principles and practice of emergency medicine, 4th ed. 1998, 232-34.

4. Committee on Medical Aspects of Automotive Safety, Rating the Severity of tissue damage: The Abbreviated Injury Scale, J Am Med Assoc. 1971;215: 277-280. https:// doi.org/10.1001/jama.1971.03180150059012.

PMID: 5107365 .

5. Association for the Advancement of Automotive Medicine Abbreviated Injury Scale 2005, Update 2008. Barrington, IL: Association for the Advancement of Automotive Medicine; 2008.

6. Shapiro SS, Wilk MB. An analysis of variance test for normality (complete samples). Biometrika. 1965 Dec 1;52 (3/4):591-611. https://doi.org/10.2307/2333709.

7. Razali NM, Wah YB. Power comparisons of Shapiro-Wilk, Kolmogorov-Smirnov, Lilliefors and Anderson-Darling tests. Journal of Statistical Modeling and Analytics. 2011; 2 (1):21-33.

8. Cramer D. Fundamental statistics for social research. Stepby-step calculations and computer techniques using SPSS for Windows. London and New York: Routledge. 1998.

9. Cramer D, Howitt DL. The Sage dictionary of statistics: a practical resource for students in the social sciences. Sage; 2004 May 18. https://doi.org/10.4135/9780857020123.

10. Doane DP, Seward LE. Measuring skewness: a forgotten statistic. Journal of Statistics Education. 2011;19(2):1-8.

11. Yartsev A, Langlois NEI. A comparison of external and internal injuries within an autopsy series. Medicine, Science and the Law. 2008 Jan 1;48(1):51-6. https:// doi.org/10.1258/rsmmsl.48.1.51.

12. Nishitani Y, Okazaki S, Suzuki K, Imabayashi K, Katada $\mathrm{R}$, Matsumoto H. The discrepant severity of external and internal injuries in a traffic accident: The cushioning effect via a human body against direct impact: Autopsy cases. The American journal of forensic medicine and pathology. 2009 Jun 1;30(2):186-7. https://doi.org/10.1097/ PAF.0b013e3181879ceb. PMID: 19465815.

13. Report on medico-legal data from the mass investigation performed by Medico-legal Society of Japan (XIV). 
Autopsy cases of traffic accidents in Japan (1990-1994). Planning and Developmental committee of the Medicolegal Society of Japan. Jpn J Legal Med. 1997;51:120-126.

14. de la Grandmaison GL, Fermanian C, Durigon M. Analysis of discrepancies between external body examination and forensic autopsy. The American journal of forensic medicine and pathology. 2008 Mar 1;29(1):40-2. https:// doi.org/10.1097/PAF.0b013e318165c77b. PMID: 19749615.

15. Subedi N, Yadav B, Jha S. Application of abbreviated injury scale and injury severity score in fatal cases with abdominopelvic injuries. Am J Forensic Med Pathol. 2014 Dec 1;35(4):275-7. https://doi.org/10.1097/ PAF.0000000000000119. PMID:25354224.

16. Subedi N, Yadav BN, Jha S, Paudel IS, Regmi R. A profile of abdominal and pelvic injuries in medico-legal autopsy. J Forensic Leg Med. 2013 Aug 31;20(6):792-6. https://doi.org/10.1016/j.jflm.2013.06.002. 23910883. 